\title{
Photochemical Investigations and ESR Triplet Spectra of Oxazine, Thiazine and Seleneazine Dyes
}

\author{
By \\ EREHARd' Vogelma.n *, HaR'TMUT SCHMid' **, \\ ULrich STEINER * and Horst E. A. KraMer *
}

\begin{abstract}
Flash photolysis experiments of the photoreduction of oxonine, thionine, and selenine showed that for all three dyes the rate constant of the electron transfer process between the reducing agent allylthiourea and the acid triplet form is considerably higher than that of the corresponding reaction with the basic form. The higher reactivity of the acid triplet form can be related to its higher redox potential which is arailable from the difference of the $p K$ values of triplet and semichinone of the dye.

The zero-field splitting parameters of ESR triplet spectra of the dyes, mentioned above, and their tetramethylsubstituted derivatives were determined.

\section{Introduction}

Studying the photoreduction of thionine $T H^{+}(X=S, R=H)$ Fischer et al. ${ }^{1}$ found that the reactivity of the acid triplet form ${ }^{3} \mathrm{TH}_{2}{ }^{+}+$towards the reducing agent allylthiourea (ATU) is considerably higher than that of the basic form ${ }^{3} T H^{\dagger}$. Meanwhile, similar results have been obtained by Joussot-Dubien et al. ${ }^{2}$ for two other thiazine dyes azur $A$ and methylene blue using ethylenediaminetetraacetic acid (FDTA) as reducing agent. The question arises whether the higher reactivity might be due to a change of the character of the lowest triplet state upon protonation $\left({ }^{3} T H^{+}\right.$having $\pi \pi^{*}$ character and ${ }^{3} \mathrm{TH}_{2}{ }^{++} n \pi^{*}$ character) or whether it may be correlated with some other property.

\footnotetext{
* Institut für Physikalische Chemie der Universität Stuttgart, Germany ** Institut für Physikalische Biochemie der Universität Frankfurt/M., Germany

1 H. Fischer, H. E. A. Kramer, and A. Maute, Z. physik. Chem. Neue Folge 69 (1970) 113 and papers cited therein.

2 R. Bonneau, Ph. Fornier de Violet and J. Joussot-Dubien, Photochem. Photobiol. 19 (1974) 129 and papers cited therein.
} 
Studying the reactivity of the acid and of the basic triplet forms in the series oxonine, thionine, and selenine $(X=O, S, S e ; R=H)$ towards ATU should give some information.

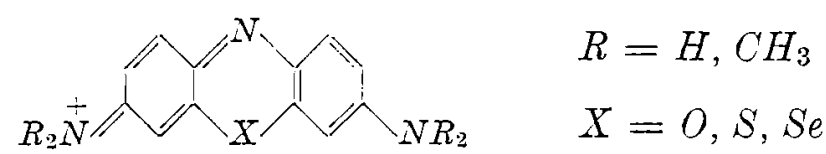

In the acid form of thionine the proton is located at the central ring $N$ atom $^{3-5}$. Since there are only small differences in the triplettriplet absorption spectra between oxonine, thionine, and selenine, we conclude that this holds for all dyes; so in the acid forms $n$ electrons are only available from the heteroatom $X$.

Furthermore, zero-field splitting (ZFS) parameters of ESR triplet spectra of these dyes could reveal either the $n \pi^{*}$ or the $\pi \tau^{*}$ character ${ }^{6,7}$ of acid and basic forms of the dye triplets*.

\section{Results and discussion}

The rate constants (see Table 1) were evaluated from flash photolysis measurements of semireduced dye production and of the decay of the dye triplet (for further details see Fischer et al. ${ }^{1}$ ). It has been demonstrated that an electron and not an $H$ atom is transferred from ATU to the dye triplets, see e.g. the thionine triplet ${ }^{9}$.

Since the oxonine triplet quantum yield is too low (solvent: methanol), its triplet was produced by triplet-triplet energy transfer using 9,10 -dibromoanthracene $\left(E_{T}=40.3 \mathrm{kcal} / \mathrm{Mole}{ }^{10}\right)$ as a sensitizer.

The lifetime of the dye triplets (see Table 1) decreases from oxonine to selenine which might be due to increasing spin-orbit coupling. It is interesting to note that the lifetime of the acid form is shorter

* With the phosphoroscope available to us (described in ${ }^{8}$ ) we were not able to detect any phosphorescence of the dyes.

3 U. Sommer and H. E. A. Kramer, a) Photochem. Photobiol. 13 (1971) 387 ; b) Z. physik. Chem. Neue Folge 67 (1969) 163.

4 O. Chalvet, J. Hoarau, J. Joussot-Dubien and J.-C. Rayez, J. Chim. physique 69 (1972) 630.

э J.-C. Rayez and O. Chalvet, J. Chim. physique 69 (1972) 1545.

${ }^{6} \mathrm{H}$. Schuid t, Photochem. Photobiol. 11 (1970) 17.

7 H. Sternlicht, J. chem. Physics 38 (1963) 2316.

$8 \mathrm{M}$. GLANDIEN, thesis, University of Stuttgart, 1971.

9 U. Steiner, M. HafNer, S. Schreiner, and H. E. A. Kramer, Photochem. Photobiol. 19 (1974) 119.

10 S. P. MCGLYNN, T. AzUmi, and M. Kasha, J. chem. Physics 40 (1964) 507. 
Table 1. Rate constants of the basic and acid forms of oxonine, thionine, and selenine dye triplets obtained by flash photolysis (see text)

Solvent: methanol; reducing agent: A'TU; oxygen-free

\begin{tabular}{l|c|c|c|c|c}
\hline \multirow{2}{*}{ Dye } & \multicolumn{4}{|c}{ Basic triplet form } \\
\cline { 2 - 6 } & $\begin{array}{c}\text { Dye } \\
\text { conc. } \times 10^{6} \\
{[\mathrm{M}]}\end{array}$ & $\begin{array}{c}\left(k_{6}+k_{8}\right) \\
\times 10^{-6} \\
{\left[\mathrm{M}^{-1} \mathrm{~s}^{-1}\right]}\end{array}$ & $\begin{array}{c}k_{7} \times 10^{-6} \\
{\left[\mathrm{M}^{-1} \mathrm{~s}^{-1}\right]}\end{array}$ & $\frac{k_{7}}{k_{6}+k_{7}}$ & $\tau_{0}[\mu \mathrm{s}]$ \\
\hline Oxonine $^{\mathrm{a}}$ & 4 & 1.8 & 1.1 & 0.60 & 140 \\
Thionine $^{9}$ & 4 & 3.2 & 1.7 & 0.55 & 40 \\
Selenine & 4 & 6.9 & 5.1 & $>0.75$ & 21 \\
\end{tabular}

\begin{tabular}{|c|c|c|c|c|c|c|}
\hline \multirow[b]{2}{*}{ Dye } & \multicolumn{6}{|c|}{ Acid triplet form } \\
\hline & $\begin{array}{c}\text { Dye } \\
\text { conc. } \times 10^{6} \\
{[\mathrm{M}]}\end{array}$ & $\begin{array}{c}{\left[\mathrm{H}_{3} \mathrm{PO}_{4}\right]} \\
{[\mathrm{M}]}\end{array}$ & $\begin{array}{c}\left(k_{6}^{\prime}+k_{7}^{\prime}\right) \\
\times 10^{-8} \\
{\left[\mathrm{M}^{-1} \mathrm{~S}^{-1}\right]}\end{array}$ & $\begin{array}{r}k_{7}^{\prime} \times 10^{-8} \\
{\left[\mathrm{M}^{-1} \mathrm{~S}^{-1}\right]}\end{array}$ & $\frac{k_{7}^{\prime}}{k_{6^{\prime}}+k_{7^{\prime}}}$ & $\tau_{0}^{\prime}[\mu \mathrm{s}]$ \\
\hline Oxonine ${ }^{a}$ & 4 & $10^{-1}$ & 0.86 & 0.43 & 0.50 & 55 \\
\hline Thionine $^{9}$ & 20 & $10^{-2}$ & 6.6 & 3.6 & 0.55 & 17.5 \\
\hline Selenine & 20 & $10^{-1}$ & 6.4 & 4.0 & 0.62 & $0.4^{\mathrm{b}}$ \\
\hline
\end{tabular}

a Sensitizer: 9,10-dibromoanthracene $1.5 \times 10^{-4} \mathrm{M}$.

b Obtained by a ruby laser with doubled frequency.

Meaning of the rate constants ${ }^{1}$.

${ }^{3} D H^{+}+A T U \stackrel{k_{\imath}}{\rightarrow}$ semireduced dye $+A T U^{+\cdot} ;{ }^{3} D H^{+}+A T U \stackrel{k_{0}}{\rightarrow}{ }^{1} D H^{+}$ $+A T U ;{ }^{3} D H^{+}+1 / \tau_{0} \rightarrow{ }^{1} D H^{+}$.

The primed rate constants are related to the acid triplet form.

than that of the corresponding basic one. For all three dyes the rate constant $k_{7}{ }^{\prime}$ of the electron transfer process between ATU and the acid triplet form is considerably higher than that of the corresponding reaction with the basic form.

From the ZFS parameters $D^{*}(\Delta m=2)$ (notation see ${ }^{6}$ ) presented in Table 2 it can be concluded that both basic and acid form of the oxonine triplet are of $\pi \pi^{*}$ character. This conclusion is based on the theoretical argument, that on excitation of an $n$ electron of small atoms there may result a comparatively large value for the spin-spin interaction energy which is due to a one centre integral ${ }^{7}$. Considering only this integral SternLicht ${ }^{7}$ derived a formula for $D$ and $E$ which applies to $n \pi^{*}$ triplet states with the $n$ electron from atoms of principal 
Table 2. ESR zero-field splitting parameters $\left[\mathrm{cm}^{-1} \cdot h c\right]$ and decay times (for $\Delta m=2$ ) of the dye triplets

Appropriate filters were chosen to excite only the lowest singlet state. Modulation of the exciting light (XBO $1600 \mathrm{~W}$ ), phase sensitive detection and a Time Averaging Computer $(\mathrm{CAT})$ were used. $t=-175^{\circ} \mathrm{C}$; air saturated

\begin{tabular}{|c|c|c|c|}
\hline Conc. $2 \times 10^{-1} \mathrm{M}$ & $\tau[\mathrm{msec}]$ & $D^{*}(\Delta m=2)$ & $D^{*}(\Delta m=1)$ \\
\hline Oxonine & $\begin{array}{cc}\mathrm{a} & 30 \pm 10 \\
\mathrm{~b} & \mathrm{c}\end{array}$ & $\begin{array}{l}0.067 \pm 0.001 \\
0.057 \pm 0.002\end{array}$ & $\begin{array}{l}\mathrm{c} \\
\mathrm{c}\end{array}$ \\
\hline Tetramethyloxonine & $\begin{array}{ll}\text { a } & 40 \pm 10 \\
\text { b } & \end{array}$ & $\begin{array}{l}0.058 \pm 0.001 \\
\text { no signal }\end{array}$ & c \\
\hline Thionine & $\begin{array}{cc}\mathrm{a} & 3.5 \pm 0 . \tilde{5} \\
\mathrm{~b} & 2 \pm 1\end{array}$ & $\begin{array}{l}0.069 \pm 0.001 \\
0.060 \pm 0.001\end{array}$ & $\begin{array}{l}0.0664 \\
0.0554\end{array}$ \\
\hline Methylene Blue & $\begin{array}{ll}\mathrm{a} & 2 \pm 0.5 \\
\mathrm{~b} & \end{array}$ & $\begin{array}{l}0.066 \pm 0.001 \\
\text { no signal }\end{array}$ & 0.0600 \\
\hline Selenine & $\begin{array}{c}\mathrm{a} \\
\mathrm{b}\end{array} \underset{\mathrm{c}}{0.4^{\mathrm{d}}}$ & $\begin{array}{l}0.082 \pm 0.001 \\
0.062 \pm 0.002\end{array}$ & $\begin{array}{l}0.0836 \text { or } 0.0705 \\
\text { c }\end{array}$ \\
\hline Tetramethylselenine & ${ }_{\mathrm{b}}^{\mathrm{a}}<0.4^{\mathrm{d}}$ & $\begin{array}{l}0.062 \pm 0.001 \\
\text { no signal }\end{array}$ & 0.0574 \\
\hline
\end{tabular}

quantum number 2 and accounts for varying hybridization $[a \cdot(2 s)$ $+b \cdot(2 p)]$ of the $n$ orbital and for the density $\varrho$ of the electron in the lowest unoccupied $\pi^{*}$ orbital on the heteroatom $X$.

Using the definition

$$
D^{*}=\sqrt{D^{2}+3 E^{2}}
$$

one gets

$$
D^{*}=D_{\max } \sqrt{1-a^{2}+a^{4}}\left(D_{\max }=D \text { for } a=1\right) .
$$

Hence $0.86 D_{\max } \leq D^{*} \leq D_{\max }$, which means that $D^{*}$ depends only weakly on hybridization. For oxygen one obtains:

$$
D^{*} \approx 3.04 \varrho \mathrm{cm}^{-1}
$$

$\varrho$ should be in the order of magnitude of 0.02 to explain the experimental $D^{*}$ values for oxonine by $n \pi^{*}$ states. As may be seen, however, 
by comparison with $P P P$ calculations for thionine ${ }^{3 \mathrm{a}}$ and 2.7 diaminoacridine $^{3 \mathrm{~b}}$ this is very improbable. (For oxonine a value of $\varrho$ greater than 0.1 should be expected.) So the oxonine triplet forms can be assigned to $\pi \pi^{*}$ states.

For $S$ and $S e$ the one centre integrals for spin-spin interaction are considerably smaller but spin orbit coupling contributions may become of importance. Yet without a more detailed calculation, the question $n \pi^{*}$ or $\pi \pi^{*}$ cannot be decided from the $D^{*}$ parameters in this case.

One should note, however, that $D^{*}$ values of the same order of magnitude have been assigned to $\pi \pi^{*}$ triplet states of molecules of similar structure (see for comparison the results of acridine dyes ${ }^{6,11}$ ). Table 1 shows that the parameter $D^{*}$ of the acid forms is always smaller than that of the corresponding basic forms which means that in the acid form the unpaired electrons are more delocalized. The higher value of selenine might be due to a stronger spin orbit coupling. of Se.

From the experimental results we may conclude that in the case of oxonine the higher reactivity of the acid triplet form cannot be due to a change of the character, since both basic and acid triplet forms are $\pi \pi^{*}$ states. Hence, for the other dye triplets, there is no reason to postulate a change of character, although the experimental results presented in this paper (ZFS parameters and kinetic studies) do not completely rule out such a possibility.

From their investigations about the reactivity of thiazine dyes Joussot-Dubies et al. ${ }^{2}$ also inferred that the $\pi \pi^{*}$ nature of the state is kept when the triplet molecule is protonated. They attributed the greater reactivity of the acid triplet form to a smaller electron density in the two side aromatic rings produced by protonation.

According to REHM and WELLER 12 a there may be correlation between the rate constants of electron transfer processes and the redox potentials of the reacting species. The difference of redox potentials of the basic and the acid triplet form, e.g. of thionine, may be derived by the following consideration, (see also ReHMr and WeLreR 12b): The acid form $\mathrm{TH}_{2}{ }^{+}$of semithionine can be produced in two ways:

${ }^{3} \mathrm{TH}^{+}+e^{-} \rightarrow \mathrm{TH} \mathrm{H}^{\cdot}+\mathrm{H}^{+} \rightarrow \underline{\mathrm{TH}_{2}^{+\cdot}} \leftarrow e^{-}+{ }^{3} \mathrm{TH}_{2}{ }^{++} \leftarrow \mathrm{H}^{+}+{ }^{3} \mathrm{TH}^{+}$

11 H. Schмidт, Z. Naturforsch. 26a (1971) 763.

12 D. Renm and A. Weller, a) Ber. Bunsenges. physik. Chem. 73 (1969) 834 ; b) Israel J. Chem. 8 (1970) 259. 
From this we derive:

$E_{0}\left({ }^{3} T H^{+} / T H^{\cdot}\right)-E_{0}\left({ }^{3} T H_{2}{ }^{++} / T H_{2}{ }^{+\cdot}\right)=2.303 \cdot \frac{R T}{F^{+}} \cdot\left(p K_{T}-p K_{S}\right)$.

With the well known $p K$ values of thionine triplet $\left(p K_{T}=6.3\right)^{13,14}$ and semithionine $\left(p K_{S}=8.1\right)^{13,15}$ in water we find that the redox potential of the acid form is higher by $0.108 \mathrm{~V}$, a value which might well account for its higher reactivity.

\section{Acknowledgements}

We thank Professor Förster for valuable discussions and for giving us the opportunity of making use of his ruby laser. Further thanks are due to Miss S. VöLKER for carrying out the laser experiment. The help of Dr. J. M. Menter, Birmingham, Alabama, USA, in translating the manuscript is gratefully acknowledged. We thank the Fonds der Chemischen Industrie and the Deutsche Forschungsgemeinschaft for their financial assistance.

${ }^{13}$ H. Fischer, Z. physik. Chem. Neue Folge 43 (1964) 177.

14 J. Faure, R. Bonneau, and J. Joussot-Dubren, Photochem. Photobiol. 6 (1967) 331.

15 R. Bonneau, J. Faure and J. Joussot-Dubien, Ber. Bunsenges. physik. Chem. 72 (1968) 263. 